\title{
Green switch: an IoT based energy monitoring system for mabini building in De La Salle Lipa
}

\author{
Oscar Bryan M. Magtibay ${ }^{1}$, Rodelio H. Cabrera ${ }^{2}$, Joselito P. Roxas ${ }^{3}$, Mark Anthony De Vera ${ }^{4}$ \\ ${ }^{1,2,3}$ Electrical Engineering Department, De La Salle Lipa, Batangas, Philippines \\ ${ }^{4}$ Computer Science Department, De La Salle Lipa, Batangas, Philippines
}

\begin{tabular}{l} 
Article Info \\
Article history: \\
Received Jan 13, 2021 \\
Revised Aug 30, 2021 \\
Accepted Sep 7, 2021 \\
\hline Keywords: \\
Building management systems \\
Grafana \\
InfluxDB \\
Internet of things \\
NodeMCI \\
Node-red \\
Raspberry Pi
\end{tabular}

\section{Article Info}

Article history

Received Jan 13, 2021

Revised Aug 30, 2021

Accepted Sep 7, 2021

\section{Corresponding Author:}

Oscar Bryan M. Magtibay

Electrical Engineering Department

De La Salle Lipa

1962 J. P. Laurel Highway Lipa, Batangas, Philippines

Email: oscar.bryan.magtibay@dlsl.edu.ph

\begin{abstract}
Building energy management systems (BEMS) are critical tools for managing and controlling a facility's technical systems and services, such as lighting, ventilation, heating, and air conditioning, to ensure that the building operates at peak efficiency while decreasing energy waste. The Mabini Building at De La Salle Lipa has nearly a hundred rooms, 70 of which are used by college students for lecture and laboratory classes. From 7:30 a.m. to 9:00 p.m., these rooms are available. In a daily class schedule, air conditioning units and lights are used an average of 10 hours per day, while fans and power outlets are used an average of 5 hours. Even when no classes are being held, the aforementioned equipment is frequently left open in these rooms. The researchers created and constructed an IoT-based energy monitoring system to monitor and control the lights and outlets in a room. The system will also record the number of kilowatt-hours $(\mathrm{kWh})$ consumed. The system employs NodeMCU, current, and voltage sensors, a Raspberry Pi 3, and the school's existing network to send and receive data from the server. The building administrator will use the collected data to give consumption statistics and reduce the carbon footprint.
\end{abstract}

This is an open access article under the CC BY-SA license.

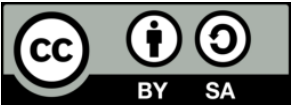

\section{INTRODUCTION}

The internet of things (IoT) is a system that includes connected devices that gather data, are connected to the Internet or local networks, generate analytics, and (in some cases) adapt behavior/responses based on the generated data through the network. It is made up of three components: sensors, networks, and analytics. Sensors are electronic devices that generate useful data that is then transmitted over a network. Networks connect devices to data centers or servers. Analytics assists in the interpretation of meaningful data in order to optimize and improve the operation of a specific infrastructure [1].

De La Salle Lipa (DLSL) is a Philippine educational institution located in Lipa City, Batangas. Within the 10-hectare lot, there are over 15 buildings, the majority of which are occupied by Integrated School and College facilities. Around 70\% of the rooms in one of DLSL's buildings, the Mabini Building, are used by college students for lecture and laboratory classes. These rooms are available from 7:30 a.m. to 9:00 p.m. In a typical class schedule, air conditioners and lights are used for an average of 10 hours per day, while fans and power outlets are used for an average of 5 hours per day. Even when there are no classes, the abovementioned equipment is frequently left open in these rooms. 
Table 1 shows the energy consumption in kilowatt-hour $(\mathrm{kWh})$ of a lecture room in the Mabini building. The total $\mathrm{kWh}$ consumption of a lecture room per month is $678.56 \mathrm{kWh}$. With 70 classrooms and an electric utility company price per $\mathrm{kWh}$ of 8 pesos per $\mathrm{kWh}$ (according to the De La Salle Lipa General Services Department), the lecture rooms of the Mabini building consumed 47,499.2 kWh, resulting in an energy cost of $379,993.6$ pesos.

Table $1 . \mathrm{kWh}$ consumption of a lecture room in mabini building

\begin{tabular}{lccccc}
\hline \multicolumn{1}{c}{ Equipment } & Qty & kW rating & Hours & kWh per day & kWh per month \\
\hline Airconditioning units & 2 & 1.4914 & 10 & 29.828 & 596.56 \\
Lights & 8 & 0.01 & 10 & 0.8 & 16 \\
Ceiling fans & 4 & 0.075 & 5 & 1.5 & 30 \\
Power outlets & 2 & 0.18 & 5 & 1.8 & 36 \\
& & & & Total kWh & 678.56 \\
\hline
\end{tabular}

In line with this, the researchers created an IoT-based energy monitoring system that tracks kWh consumption and controls the lights, fans, air conditioning, and outlets in a room. The system uses the WiFi network to transmit and receive information to and from the server. The stored data will be used by the building administrator to improve energy waste reduction. It specifically seeks to accomplish the following:

1) To prepare the project plan of the study:

- User and hardware requirements for the specifications of the system that will determine the architecture of the system

- Block diagrams and schematic diagrams

- Electrical layouts of the system

2) To construct and assemble the hardware of the project.

3) To create the database and software application that will control and monitor the energy consumption of the electrical equipment in the room.

4) To test the system and evaluate the results.

Figure 1 shows the operational framework of the study. The energy management system shown in the figure has server and the utility monitoring and control web application acted as the data logger and repository in which client devices such as smartphones and computers attempt to access the devices in the rooms to track and control them. The control module houses the sensors and relays that have acquired the appliance's power consumption and control switch. Many of the peripherals are connected to the room's access point.
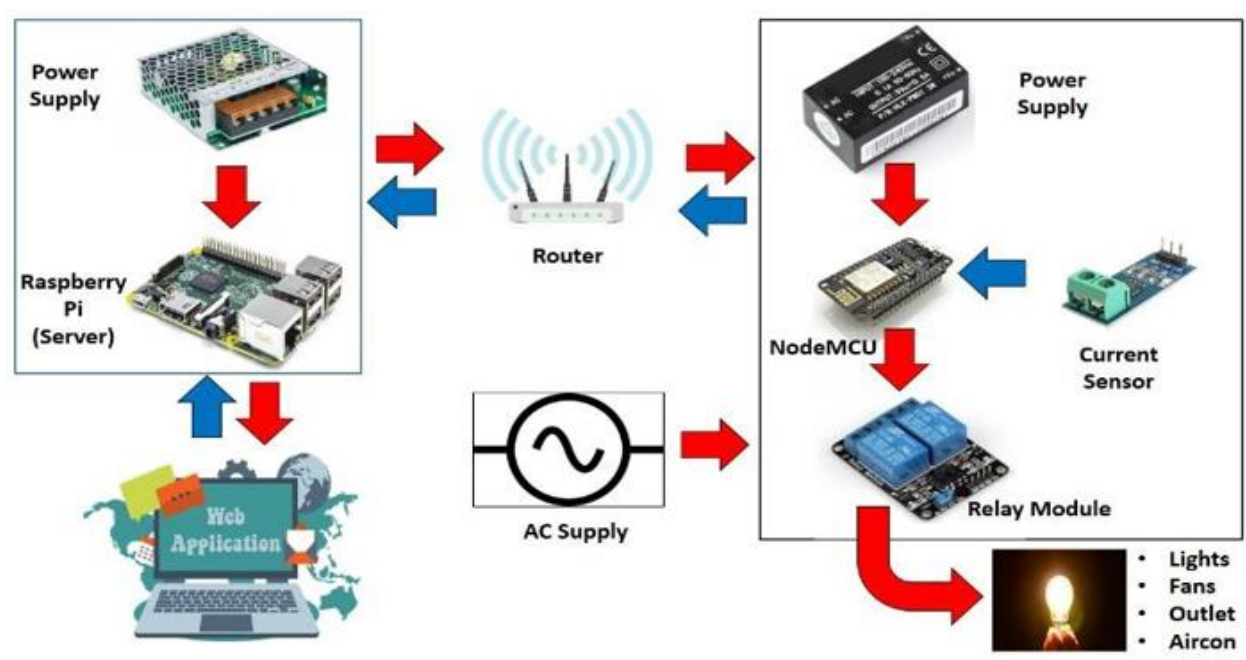

Figure 1. Operational framework

Message queuing telemetry transport (MQTT) [2] is a protocol used in the "internet of things". It's a simple publish/subscribe messaging system. It is used to connect networks with remote locations where a small footprint code is required, or network bandwidth is limited. Node-RED, developed by the emerging technology services team at international business machines (IBM) Corporation and now part of the JS foundation, is a flow-based programming tool. It is a way of defining the functions of an application as a black-box network, or 'nodes' as they are called in Node-RED. Each node has a function that is well defined [3]. 
The study of Mowad et al. [4] used Android smartphones to control devices and monitor the security at home wirelessly using Bluetooth. David et al. [5] incorporated both internet and Bluetooth communication protocol to manipulate appliances remotely from home. It uses hypertext transfer protocol (HTTP) to interact from the Arduino microcontroller installed with WiFi module which is the micro-server where the smartphone or polycarbonate (PC) can connect. Al-thobaiti et al. [6] discussed on using WiFi communication where the user uses his smartphone or PC to interact to a server where the Arduino microcontroller communicating via Serial means. With this, the user controls the appliances at home. Hasan et al. [7] used ATMEGA16 microcontroller, Bluetooth protocol to control appliances and GSM module which also used in the study of Rana et al. [8] and Anandan et al. [9] to monitor the security at home. Narrowband power line communication (N-PLC) was utilized by Bautista et al. [10] to connect the server to the service node where the utilities are connected. Astier et al. [11] have adapted the Malte concept [12] to Ippolito's technological management systems and control logics [13]. They discussed the use of Modbus/ TCP, HTML/JavaScript and structured query language (SQL) as alternative and cost-effective solution in the deployment of an IoT based building management system. It also provides a uniform supervision across all connected devices from building control equipment and data acquisition devices.

Kashyap et al. [14] used the MQTT protocol, which was also implemented for data transmission in the Atkomo et al. study [15] and the use of WiFi interface in the study of Nasrin and Radcliffe [16]. It's a publisher and subscriber-based communication protocol that enables many devices to communicate with one another across a wireless network. Jaloudi [17] discussed the use of the MQTT protocol for the IoT in a Smart City application. The system uses components such as Arduino, which was used in the data acquisition of Diaa and Mahmood [18], ESP8266 and Raspberry Pi. Discussed in the study, the MQTT, which is in the discussion of Lohokare [19], is suitable for small-to-medium IoT-based business applications that use cloudbased servers and for medium-to-big business applications that rely on LANs and Intranet. Tabaa et al. [20] used Modbus protocol to connect industry-based sensors and controller to a single on-board computer and wirelessly connect to the network using MQTT and Node-RED application which was also used in Hajovsky et al. [21]. The study of Yokotaini and Sasaki [22] discusses the advantages of and MQTT network over Http on the rate of sending and receiving transmission to devices due to its lightweight in nature of publishing and subscribing to a particular topic which the Http does not have. Suparman and Jong [23] research employs an Arduino with an ESP 8266 shield and a MQ-2 sensor enclosed in a 3D printed enclosure. To send notifications to the Fire Rescue Department, the uses the cloud IoT platform Favoriot. Hussein and Shujaa [24] research on vehicle-to-vehicle voice chat employs the MQTT protocol for central monitoring and tracking of ambulances, thereby alleviating traffic congestion and avoiding the use of traditional sirens.

\section{RESEARCH METHOD}

The engineering planning and design research method was used in this study. It is a methodical approach that entails conducting technical research to solve a problem, solving the problem by developing a model to achieve the desired solution, and testing the effectiveness of the solution. The Energy Management in De La Salle Lipa, Mabini Building is divided into two (2) components:

- Design and development of the hardware which consist of the data acquisition and controls.

- Design and implementation of the software application that will be used for building administration.

Table 2 shows the system hardware requirement. The power supply will turn on the entire system. It will convert a standard 220-volt AC supply to 5 volts DC to power the hardware's components. The microcontroller will be the system's brain, converting the signal from the sensor, transmitting data via WiFi, and controlling the room's lights and outlets. The current sensor will measure the current flowing through the lights and outlets. Depending on the microcontroller instructions, the relay will switch the lights and outlets.

Table 2. Hardware requirements

\begin{tabular}{ll}
\hline \multicolumn{1}{c}{ Hardware } & \multicolumn{1}{c}{ Description } \\
\hline AC-DC Power Supply & Power source of the data acquisition device \\
Microcontroller & Serves as the controller and will connect to the server wirelessly \\
Current Sensor & Used to measure current \\
Relay & Used to switch the light and outlets \\
\hline
\end{tabular}

Figure 2 show the connection diagram of the hardware and the lctrical layout in which the hardware is installed in an outlet or a switch. The current sensor is connected to one line of the outlet to calculate the current. The 5 volt power supply is used to power the ESP8266 microchip-based opensource microcontroller, NodeMCU [25]. The sensor output is connected to the NodeMCU's analog A0. The relay module is 
connected to Pin D2 of the microcontroller. The NodeMCU microcontroller's function is to acquire data from the device's sensor control via WiFi communication. The electrical layout uses a two-wire configuration to make the connection more convenient. To power the system, an existing outlet with a 220 volt AC source is connected to the hardware's L1 and L2. T1 and T2 output terminals are connected to the load.
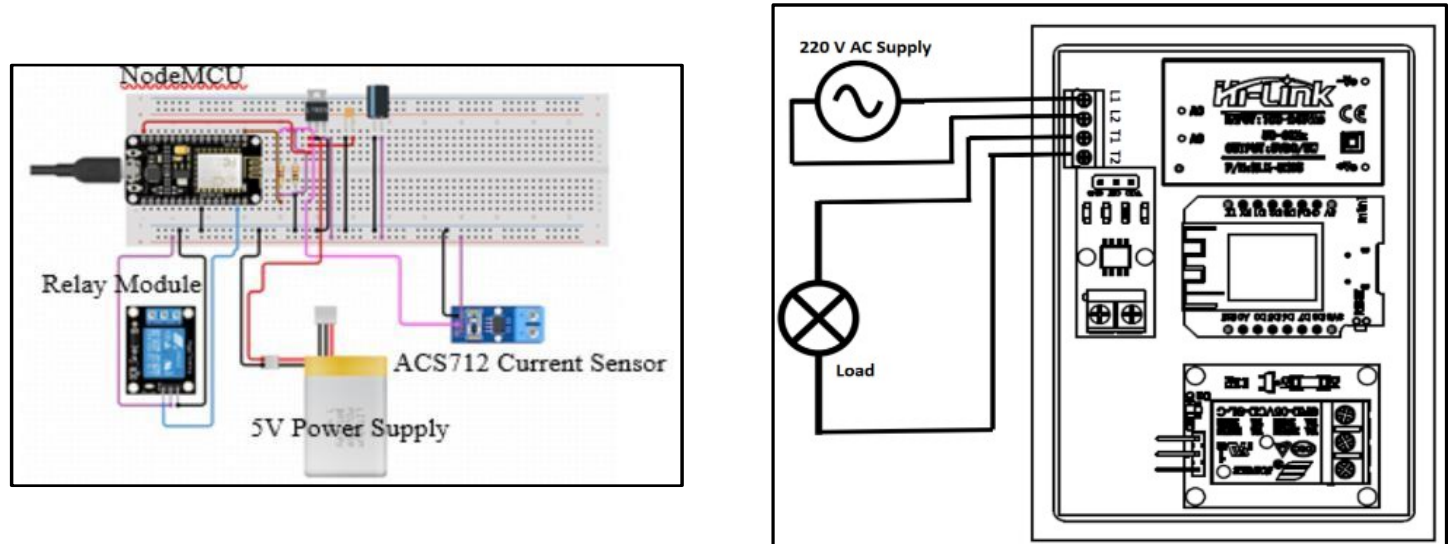

Figure 2. Connection diagram of the control node and electrical layout

Figure 3 shows the actual node hardware of the system. The dimension of the hardware is $95 \mathrm{~mm} \mathrm{x}$ $70 \mathrm{~mm} \times 35 \mathrm{~mm}$. It comprises the electronic components inside the enclosure. The enclosure of the hardware is $3 \mathrm{D}$ printed using printer plastic (PLA) plastic. The electronic components are soldered together on the printed circuit board. The board then is installed inside the enclosure.

Table 3 shows the software requirements in building the web application. The Arduino integrated development environment (IDE) is open-source programming software for microcontrollers [23]. Node-red is a node-based programming language used to create web-based applications. InfluxDB is a free and opensource time series database for archiving and storing data [26]. Grafana is an open-source monitoring solution that provides graphical data for a project [27]. The Node-red framework is written on the Raspberry Pi 3 server, a credit-card-sized single-board computer [28] that also serves as the system's MQTT broker. Each MQTT topic node is intended to keep track of each server-controlled appliance. Influx DB and Grafana, which serve as the database and web-based visualization, are also installed on the Raspberry Pi. Figure 4 shows the system architecture. In the system architecture, the hardware nodes, which are made up of sensors, relays, and a microcontroller, collect power data from the lights and fans and act as a switch for the appliances. WIFI was used to transmit the data, which was then routed to the server. The software application collected data on the power consumption of the appliances on an hourly basis.

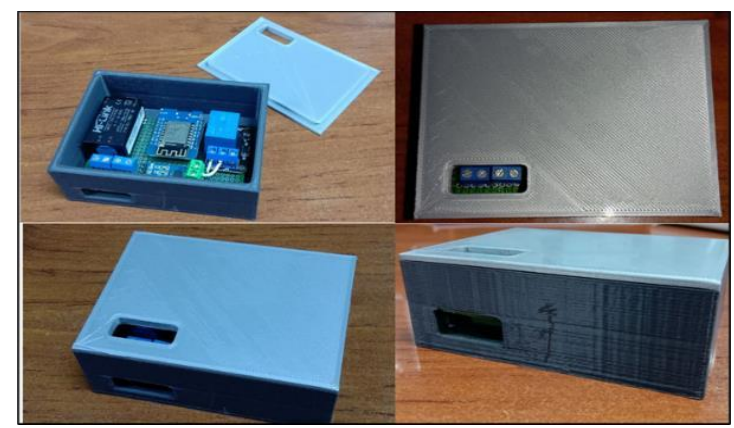

Figure 3. Node hardware

Table 3. Software requirements

\begin{tabular}{ll}
\hline \multicolumn{1}{c}{ Software } & \multicolumn{1}{c}{ Description } \\
\hline Arduino IDE & Programming software for the Microcontroller \\
Node-red & Web-based prgramming software \\
InfluxDB & Database \\
Grafana & Web-based monitoring solution \\
\hline
\end{tabular}




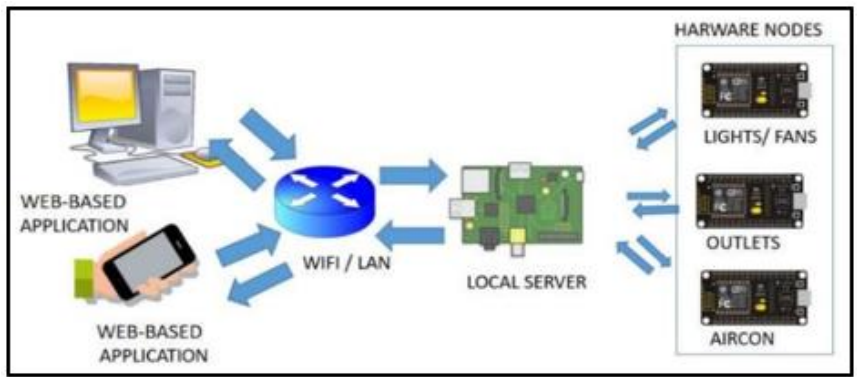

Figure 4. System architecture

\section{RESULTS AND DISCUSSION}

Figure 5 shows how the node hardware is installed in the simulation board. The hardware module is installed to the simulation board's respective lights and outlets, as shown in the Figure 5. Each hardware module is linked to a light or outlet and can be individually controlled. All of the node hardware is wirelessly connected via a wireless router, and each node subscribes to a different MQTT topic.

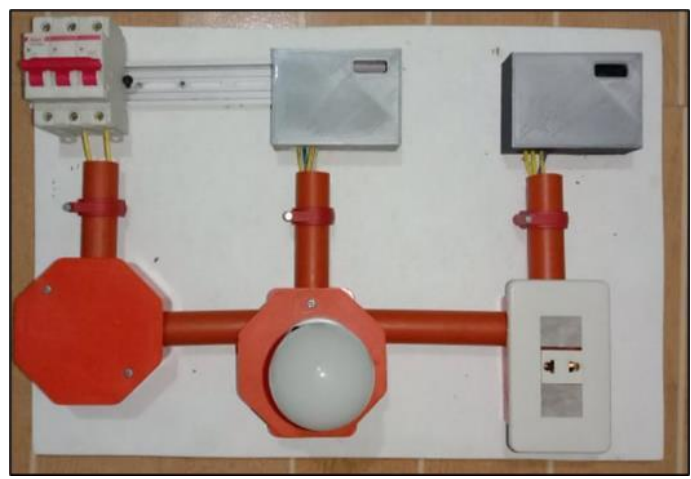

Figure 5. Installed hardware module on simulation board

The web-based interface is shown in Figure 6. The web-based application displays control for the hardware nodes, real-time power, and a graph of the power trend. The web application is accessible from any device with a browser, such as Microsoft Edge, Safari, Firefox, or Google Chrome.

Historical trend is shown in Figure 7. The Grafana interface displays the amount of power consumed per hour by a specific appliance. This provides the user with an overview of how much they spent per day on a specific appliance. Figure 8 shows the hardware node connection in to the network. The hardware nodes can be seen in the dynamic host configuration protocol (DHCP) list, and the connection to the server can be seen. The web application responds in 1 to 2 seconds to control and monitor the hardware nodes.

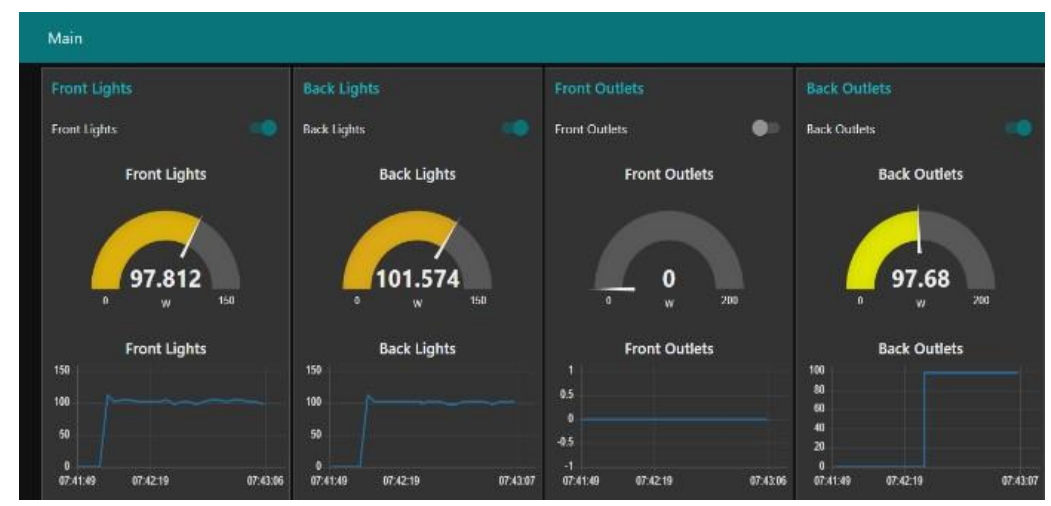

Figure 6. Web-based application 


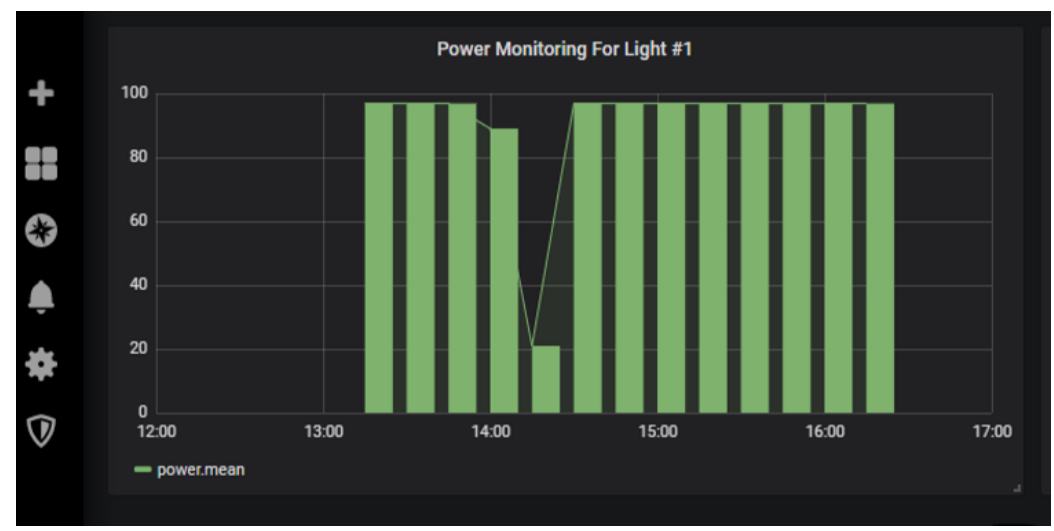

Figure 7. Grafana interface for historical data

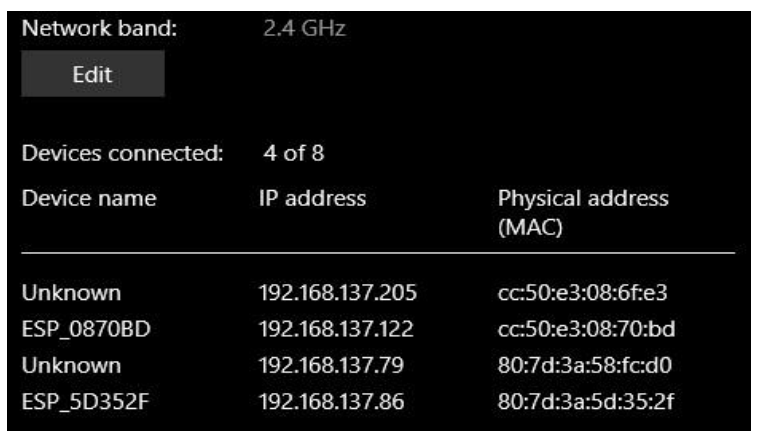

Figure 8. Connection of the hardware node to the network

Table 4 was made to compare current structures based on the project was made to validate the solution. Current devices use Bluetooth, which limits the ability of devices to be monitored outside the home. Each appliance must be paired with a smartphone in order to be monitored. Others use a PC server that consumes at least 200 watts of power, which is excessive given the control of appliances. The use of Arduino as an HTTP webserver limits versatility to external functions such as the database due to its limited memory. It can be seen that using a single data protocol, such as MQTT, simplifies and improves the system, especially for microcontrollers. Using Node-red provides an easy-to-use web-based user interface with no device installation for both smartphones and PCs.

Table 4. Table of comparison based on related literature

\begin{tabular}{|c|c|c|c|c|}
\hline IoT Systems & Protocols & Controller Node and Server & Application & Accessibility \\
\hline Mowad, Ahmed and Ahmed (2014) [4] & Bluetooth and RF & $\begin{array}{l}\text { Arduino with Bluetooth module } \\
\text { and PIC with RF Module }\end{array}$ & $\begin{array}{l}\text { Phone } \\
\text { Application }\end{array}$ & Local \\
\hline $\begin{array}{l}\text { David, Chima, Ugochukwu and Obinna } \\
\text { (2015) [5] }\end{array}$ & WiFi/ Bluetooth & $\begin{array}{l}\text { Arduino with Bluetooth module } \\
\text { and PC }\end{array}$ & Web Application & Local/ LAN \\
\hline $\begin{array}{l}\text { Al-thobaiti, Abosolaiman, Alzahrani, } \\
\text { Almalki, and Soliman (2014) [6] }\end{array}$ & WiFi/ USB & Arduino and PC & Web Application & Local/ LAN \\
\hline $\begin{array}{l}\text { Hasan, Monirujjaman, Asaduzzaman, } \\
\text { Israt and Rumpa (2015) [7] }\end{array}$ & Bluetooth/GSM & $\begin{array}{l}\text { ATMEGA16 with Bluetooth and } \\
\text { GSM Module }\end{array}$ & $\begin{array}{l}\text { Phone } \\
\text { Application }\end{array}$ & Local \\
\hline $\begin{array}{l}\text { Bautista, Ong, Pineda, Urbano, Uy and } \\
\text { Dulay (2015) [10] }\end{array}$ & $\begin{array}{l}\text { Powerline } \\
\text { Communication }\end{array}$ & PLC and PC & PC Application & Local \\
\hline $\begin{array}{l}\text { Astier, Zhukov, and Murashov } \\
\text { (2017) [11] }\end{array}$ & Modbus/ LAN & RTU and Server PC & $\begin{array}{l}\text { PC/ Server } \\
\text { Application }\end{array}$ & $\begin{array}{l}\text { Local/ } \\
\text { Internet }\end{array}$ \\
\hline Project & WiFi/ Internet & ESP8266 and Raspberry Pi & Web Application & $\begin{array}{l}\text { Local/ } \\
\text { Internet }\end{array}$ \\
\hline
\end{tabular}

\section{CONCLUSION}

The conclusions were derived from the data and results. In the development of hardware, it is appropriate to determine the user and hardware requirements for specifications, block diagrams, flowcharts, schematic diagrams, and electrical layouts. The hardware is simple to assemble and implement because it makes use of the setup's existing wiring connections. The web application was designed to be user-friendly

Green switch: an IoT based energy monitoring system for mabini building ... (Oscar Bryan Magtibay) 
on both PCs and smartphones. The test provided precise measurements as well as a satisfactory response to control and monitor the appliance.

\section{REFERENCES}

[1] World Bank Group, "Internet of Things: The New Government-to-Business Platform," World Bank, Washington, DC. World Bank, pp. 9, Nov 2017, doi: 10.1596/28661.

[2] E. Longo, A. E. C. Redondi, M. Cesana, A. Arcia-Moret, and P. Manzoni, "MQTT-ST: a Spanning Tree Protocol for Distributed MQTT Brokers," ICC 2020 - 2020 IEEE International Conference on Communications (ICC), Jul 2020, pp. 1-6, doi: 10.1109/ICC40277.2020.9149046.

[3] M. Lekić and G. Gardašević, "IoT sensor integration to Node-RED platform," Apr 2018 17th International Symposium INFOTEH-JAHORINA (INFOTEH), 2018, pp. 1-5, doi: 10.1109/INFOTEH.2018.8345544.

[4] M. A. E. Mowad, F. Ahmed, and H. Ahmed, "Smart Home Automated Control System Using Android Application and Microcontroller," International Journal of Scientific \& Engineering Research, vol. 5, no. 5, pp. 935-939, May 2014.

[5] N. David, A. Chima, A. Ugochukwu, and E. Obinna, "Design of a Home Automation System Using Arduino," International Journal of Scientific \& Engineering Research, vol. 6, no. 6, pp.795-803 Jun 2015.

[6] B. M. O. Al-thobaiti, I. I. M. Abosolaiman, M. H. M. Alzahrani, S. H. A. Almalki, and M. S. Soliman, "Design and Implementation of a Reliable Wireless Real-Time Home Automation System Based on Arduino Uno Single-Board Microcontroller," International Journal of Control, Automation and Systems, vol. 3 no. 3, pp. 11-15, Jul 2014.

[7] R. Hasan, M. Monirujjaman, K. Asaduzzaman, A. A. Israt, and J. Rumpa, "Microcontroller Based Home Security System with GSM Technology," Open Journal of Safety Science and Technology, pp. 55-62, Jun 2015, doi: 10.4236/ojsst.2015.52007.

[8] G. M. S. M. Rana, A. A. M. Khan, M. N. Hoque, and A. F. Mitul, "Design and Implementation of a GSM Based Remote Home Security and Appliance Control System," 2nd International Conference on Advances in Electrical Engineering, Dec 2013, pp. 291-295, doi: 10.1109/ICAEE.2013.6750350.

[9] R. Anandan, B. Karthik, and K. Kumar, "Wireless Home and Industrial Automation and Security System Using GSM," Journal of Global Research in Computer Science, vol. 4, no. 4, pp. 126-132, Apr 2013.

[10] A. D. Bautista, E. T. Ong, N. A. G. Pineda, M. Y. V. Urbano, P. S. L. Uy, and A. E. Dulay, "Energy Management System for Educational Buildings Using Narrow Band Power Line Communications Based on the Prime Standard," Asian Research Publishing Network (ARPN) Journal of Engineering and Applied Sciences, vol. 12, no. 7, pp. 2326-2332, Apr 2017.

[11] J. Y. Astier, I. Y. Zhukov, and O. N. Murashov, "Smart Building Management Systems and Internet of Things," Bezopasnost Informacionnyh Tehnology, vol. 24, no. 3, pp. 18-29, Aug 2017, doi: 10.26583/bit.2017.3.02.

[12] M. Burkert, H. Krumm, and C. Fiehe "Technical management system for dependable Building Automation Systems," 2015 IEEE 20th Conference on Emerging Technologies \& Factory Automation (ETFA), Sep 2015, pp 1-8, doi: 10.1109/ETFA.2015.7301656.

[13] M. G. Ippolito, G. Zizzo, A. Piccolo, P. Siano, "Definition and Application of Innovative Control logics for Residential Energy Optimization," 2014 International Symposium on Power Electronics, Electrical Drives, Automation and Motion, Jun 2014, pp. 1272-1277, doi: 10.1109/SPEEDAM.2014.6872124.

[14] M. Kashyap, V. Sharma, and N. Gupta, "Taking MQTT and NodeMcu to IOT: Communication in Internet of Things," Procedia Computer Science 132, pp. 1611-1618, May 2018, doi: 10.1016/j.procs.2018.05.126.

[15] R. A. Atmoko, R. Riantini, and M. K. Hasin, "IoT real time data acquisition using MQTT protocol," Journal of Physics: Conf. Series 853, May 2017, doi: 10.1088/1742-6596/853/1/012003.

[16] S. Nasrin, and P. J. Radcliffe, "Novel protocol enables DIY home automation," Australasian Telecommunication Networks and Applications Conference (ATNAC), Nov 2014, pp. 212-216, doi: 10.1109/ATNAC.2014.7020900.

[17] S. Jaloudi, "MQTT for IoT-based Applications in Smart Cities," Palestinian Journal of Technology and Applied Science, no. 2, pp. 1-13, Mar 2019, doi: 10.5281/zenodo.2582892.

[18] M. F. Diaa, and B. M. Mahmood, "Data Acquisition of Greenhouse Using Arduino," Journal of Babylon University, Pure and Applied Sciences, vol. 22, no.7, pp. 1908-1916, 2014.

[19] O. Sadio, I. Ngom and C. Lishou, "Lightweight Security Scheme for MQTT/MQTT-SN Protocol," 2019 Sixth International Conference on Internet of Things: Systems, Management and Security (IOTSMS), Dec 2019, pp. 119-123, doi: 10.1109/IOTSMS48152.2019.8939177.

[20] M. Tabaa, B. Chouri, S. Saadaoui, and K. Alami, "Industrial Communication based on Modbus and Node-RED," The 9th International Conference on Ambient Systems, Networks and Technologies, Apr 2018, pp. 583-588, doi: 10.1016/j.procs.2018.04.107.

[21] R. Hajovsky, M. Pies, and J. Skovranek, "Use of the IQRF and Node-RED technology for control and visualization in an IQMESH network," International Federation of Automatic Contol (IFAC), pp. 295-300, 2018, doi: 10.1016/j.ifacol.2018.07.169.

[22] T. Yokotani and Y. Sasaki, "Comparison with HTTP and MQTT on required network resources for IoT," 2016 International Conference on Control, Electronics, Renewable Energy and Communications (ICCEREC), Sep 2016, pp. 1-6, doi: 10.1109/ICCEREC.2016.7814989.

[23] M. A. B. Suparman and S. L. Jong, "Automatic smoke detection system with favoriot platform using internet of things (IoT)," Indonesian Journal of Electrical Engineering and Computer Science (IJEECS), vol. 15, no. 2, pp. 1102-1108, Aug 2019, pp. 1102-1108, doi: 10.11591/ijeecs.v15.i2.pp1102-1108. 
[24] N. A. Hussein and M. I. Shujaa, "Secure vehicle to vehicle voice chat based MQTT and coap internet of things protocol," Indonesian Journal of Electrical Engineering and Computer Science (IJEECS), vol. 19, no. 1, pp. 526-534, Jul 2020, doi: 10.11591/ijeecs.v19.i1.pp526-534.

[25] A. Nayyar and V. Puri, "A review of Arduino board's, Lilypad's \& Arduino shields," 2016 3rd International Conference on Computing for Sustainable Global Development (INDIACom), Oct 2016, pp. 1485-1492.

[26] S. Di Martino, L. Fiadone, A. Peron, A. Riccabone, and V. N. Vitale, "Industrial Internet of Things: Persistence for Time Series with NoSQL Databases," Aug 2019 IEEE 28th International Conference on Enabling Technologies: Infrastructure for Collaborative Enterprises (WETICE), Jun 2019, pp. 340-345, doi: 10.1109/WETICE.2019.00076.

[27] S. Penkov, A. Taneva and R. Kazala, "Supervisory and Data Acquisition project with LoRa," 2020 International Conference Automatics and Informatics (ICAI), Oct 2020, pp. 1-4, doi: 10.1109/ICAI50593.2020.9311338.

[28] L. K. P. Saputra and Y. Lukito, "Implementation of air conditioning control system using REST protocol based on NodeMCU ESP8266," 2017 International Conference on Smart Cities, Automation \& Intelligent Computing Systems (ICON-SONICS), Nov 2017, pp. 126-130, doi: 10.1109/ICON-SONICS.2017.8267834.

\section{BIOGRAPHIES OF AUTHORS}
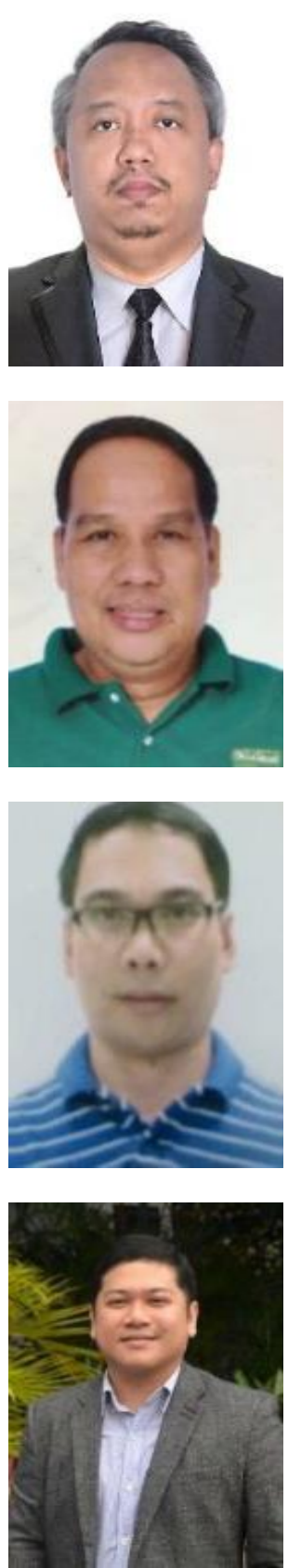

Engr. Oscar Bryan M. Magtibay ia an Assistant Professor at De La Salle Lipa. He is a Registered Electrical Engineer and holds a Masters Degree in Computer Engineering from Batangas State University. He is currently the Area Chairperson of the General Engineering Department at De La Salle Lipa. He is teaching DC/ AC Machines, Numerical Methods, Control Systems and the Automation Elective Track of the Electrical Engineering Department. His research works are focused on Automation and IoT Solutions. These research works had been presented to local, national and international conferences.

Engr. Rodelio H. Cabrera is an Assistant Professor at De La Salle Lipa. He is a Registered Electrical Engineer. He finished his Master of Engineering Program in Electrical Engineering at TUP - Manila. He held the positions of Department Head of Electrical and Industrial Engineering Departments after-which, he became the Dean of the College of Information Technology and Engineering. He teaches Electrical Circuits, Electronics, Control System, AC Apparatus and Devices and Illumination Engineering Design.

Engr. Roxas is an Assistant Professor at De La Salle Lipa. He is a Registered Electrical Engineer. He held the position of Chairman of the Electrical Engineering. He finished his Master of Engineering Program in Electrical Engineering at TUP - Manila. He teaches Differential Equations, Electrical Circuits, Control System, Electromagnetics and Electrical System Design.

Mark Anthony De Vera is an Assistant Professor at De La Salle Lipa. He finished his Masters Degree in Information Technology at DLSU - Manila. He held the position of Chairman of the Computer Science after-which, he became the Vice-Dean of the College of Information Technology and Engineering. He teaches Computer Programming, Object Oriented Programming, Web Development and Software Engineering. His research works are focused on IoT Solutions, Web Development and Educational Technologies. These research works had been presented to local, national and international conferences. 